\title{
ArcheoSciences
}

Revue d'archéométrie

\section{Synchrotron Radiation Induced X-Ray Fluorescence for the characterization of ancient gold objects}

Fluorescence de rayons $X$ induite par radiation de synchrotron pour la caractérisation d'objets anciens en or

Martin Radtke, Uwe Reinholz and Heinrich Riesemeier

\section{OpenEdition}

\section{Journals}

Electronic version

URL: https://journals.openedition.org/archeosciences/1969

DOI: 10.4000/archeosciences. 1969

ISBN: 978-2-7535-1598-7

ISSN: 2104-3728

Publisher

Presses universitaires de Rennes

Printed version

Date of publication: 31 December 2009

Number of pages: $39-44$

ISBN: 978-2-7535-1181-1

ISSN: 1960-1360

\section{Electronic reference}

Martin Radtke, Uwe Reinholz and Heinrich Riesemeier, "Synchrotron Radiation Induced X-Ray

Fluorescence for the characterization of ancient gold objects", ArcheoSciences [Online], 33 | 2009,

Online since 09 December 2012, connection on 28 January 2022. URL: http://

journals.openedition.org/archeosciences/1969 ; DOI: https://doi.org/10.4000/archeosciences. 1969

Article L.111-1 du Code de la propriété intellectuelle. 


\title{
Synchrotron Radiation Induced X-Ray Fluorescence for the characterization of ancient gold objects
}

\author{
Fluorescence de rayons $X$ induite par radiation de synchrotron \\ pour la caractérisation d'objets anciens en or
}

\author{
Martin Radtke*, Uwe Reinholz* and Heinrich Riesemeier*
}

\begin{abstract}
Due to their non-destructive character, X-ray analytical methods are widespread in the field of archaeometry. In the present study, the use of synchrotron radiation induced X-ray fluorescence analysis (SR-XRF) is illustrated on three examples: a silver point drawing of Jan van Eyck, the Hiddensee Gold Treasure, and the Sky Disc of Nebra. The possibility to analyse large objects in normal atmosphere results in information regarding their origin, uniformity, and the manufacturing process.

Résumé : Grâce à leur non-destructivité, les techniques analytiques qui utilisent les rayons $X$ sont très répandues dans le domaine de l'archéométrie. L'utilisation de la fluorescence de rayons X induite par radiation de synchrotron (SR-XRF) est illustrée à partir de trois exemples : les dessins à pointe d'argent de Jan van Eyck, le trésor de Hiddensee et le disque céleste de Nebra. L'analyse d'objets, même de grandes tailles, à l'air permet d'obtenir des informations sur leur origine, leur homogénéité et leurs techniques de fabrication.
\end{abstract}

Keywords: Gold, Hiddensee Treasure, Nebra Sky Disc, non-destructive testing, silver point drawings, synchrotron, X-ray fluorescence.

Mots-clés : Or, trésor d'Hiddensee, disque céleste de Nebra, analyse non-destructive, dessins à pointe d'argent, synchrotron, fluorescence à rayons X.

\section{INTRODUCTION}

Synchrotron radiation (SR) is one of the most versatile tools for the characterization of materials. It combines high spatial resolution with good detection limits, the possibility to work in normal atmosphere with the capacity to examine large objects, which do not fit into sample chambers. SR measurements on metals are non-destructive.

Technically, a synchrotron is a machine which generates brilliant beams of light by moving electrons through a strong magnetic field. This light, called synchrotron radiation, ranges from the infrared to hard $\mathrm{X}$-rays, with some extremely useful properties. Additionally, a synchrotron provides the infrastructure for a number of different measuring techniques, and the facilities for sample treatment and preparation. Last but not least, synchrotrons are located in government funded science centre, where measurements can be carried out for free, provided that a beam time proposal was evaluated successful by an independent beam time committee. One of the disadvantages is that, even if there are now around 40 synchrotron light sources worldwide and the number is still increasing significantly, not every country has a synchrotron. Due to limitations related to moving precious objects and their crossing national boundaries, access

*BAM Federal Institute for Materials Research and Testing-Richard-Willstätter-Straße 11, 12489 Berlin, Germany. (martin.radtke@bam.de), (uwe. reinholz@bam.de), (heinrich.riesemeier@bam.de) 
to this methodology is limited. In any case, because of its high flux, SR-based techniques can usually be performed on minute samples.

\section{Methods}

SR is useful for all X-ray techniques; however, for the analysis of ancient metal objects, X-ray fluorescence is the predominant method. For XRF, the use of SR presents especially the following advantages:

The radiation is linearly polarized, and therefore the scattering in the plane of polarization is minimized and detection limits are improved.

The excitation energy can be selected and adapted to the problem. It is possible to excite an element of interest just above the absorption edge in order to optimize excitation, or to go under an absorption edge to avoid excitation.

SR has high brilliance. This means that the photons are emitted in a small solid angle, and this allows focusing the radiation effectively in a small excitation spot.

All examples referred to in this publication have been selected from measurements carried out with the SR-XRF setup at the BAMline at BESSY II, Berlin. At this beam line, a super conducting wavelength shifter with a maximum field of 7 Tesla is the X-ray source, with a useable energy range from $5 \mathrm{keV}$ up to $80 \mathrm{keV}$. Therefore, nearly all elements can be detected by measurement of their K-shell fluorescence. A W/Si double-multilayer-monochromator (DMM) and/or a Si [111] double-crystal-monochromator (DCM) are used to select the desired excitation energy. In order to achieve higher fluxes, it is possible to focus the beam to a size of approximately $(300 \times 300) \mu \mathrm{m}^{2}$ by bending one multilayer and/or one crystal (Görner et al., 2006). If smaller beam sizes are necessary, compound refractive lenses (CRL) can be used to achieve spot sizes of less than $(2 \times 2) \mu m^{2}$ (Strub et al., 2008). For the detection of the fluorescence signal, different types of solid state detectors ( $\mathrm{Si}(\mathrm{Li}) \mathrm{HPGe}$ and $\mathrm{SDD})$ are available. For data evaluation, various program packages are freely available. At the BAMline, QXAS from the IAEA, a Monte Carlo code, capable of simulating photon-matter interaction (Vincze et al., 1995) and pyMCA (Sole et al., 2007) are implemented. Details about the SR-XRF technique can be found elsewhere (Adams et al., 1998).

SR-XRF is a non-destructive multi-element method. However, not all elements can be analyzed with the same sensibility. For gold, an excitation energy of around $33-38 \mathrm{keV}$, depending on the expected trace elements, has been found to be most useful. In this case, the minimum detection limits (MDL) of trace elements in gold are in the order of $1 \mathrm{ppm}$. The detection of platinum requires special procedures because of the closeness of these two elements in the periodic table. By a very sophisticated approach (Guerra et al., 2005; 2008), the MDL of Pt can be decreased as low as $10-20 \mathrm{ppm}$.

\section{EXAMPLES}

If an archaeologist or art historian comes to use a synchrotron, typically one of these questions is asked:

- What material was used to manufacture this object?

- How was it made?

- Is it possible to discriminate different compositions within one object or between different members of a group of objects?

Examples of questions that are more difficult to answer are the following:

- Where does it come from?

- When was it made?

- Is the object authentic or a forgery?

Unfortunately, there is no possibility to measure the age of a gold object with SR. Therefore, the last two questions cannot be answered with our methods in a straightforward manner. In the following, examples of answers to the other categories of questions are presented. At first, the apparently trivial task of the identification of the material is illustrated by the non-destructive analysis of silver point drawings of Renaissance artists. For this purpose, extremely sensitive synchrotron - or accelerator-based techniques (PIXE - Particle Induced X-Ray Analysis) are necessary, because only small quantities of metal were deposited on the paper (Reiche et al., 2004a). On Van Eyck's drawing, the 'Portrait of Cardinal Albergati', at least three different metal points have been identified (Fig. 1). Two different types of silver marks have been found in the examined portrait. Silver containing gold marks has been detected in the inscriptions and over-subscriptions. This discovery has represented the first evidence of the use of gold points in metal point drawings from the Middle Ages. The fact that a gold stylus different from the other silver points was used represents therefore an important result. An explanation of the exceptional use of a gold stylus could be the difference in mechanical properties of a gold point, which is much smoother than pure or especially $\mathrm{Cu}$-containing silverpoints. Thus, it seems easier to write with a gold point than with a silver one. Furthermore, it is possible to obtain different colour aspects of the marks when using another metal than silver. A gold stylus leaves a dark grey mark, whereas a silver mark becomes brownish quite rapidly. Thus, it can be postulated that Van Eyck con- 


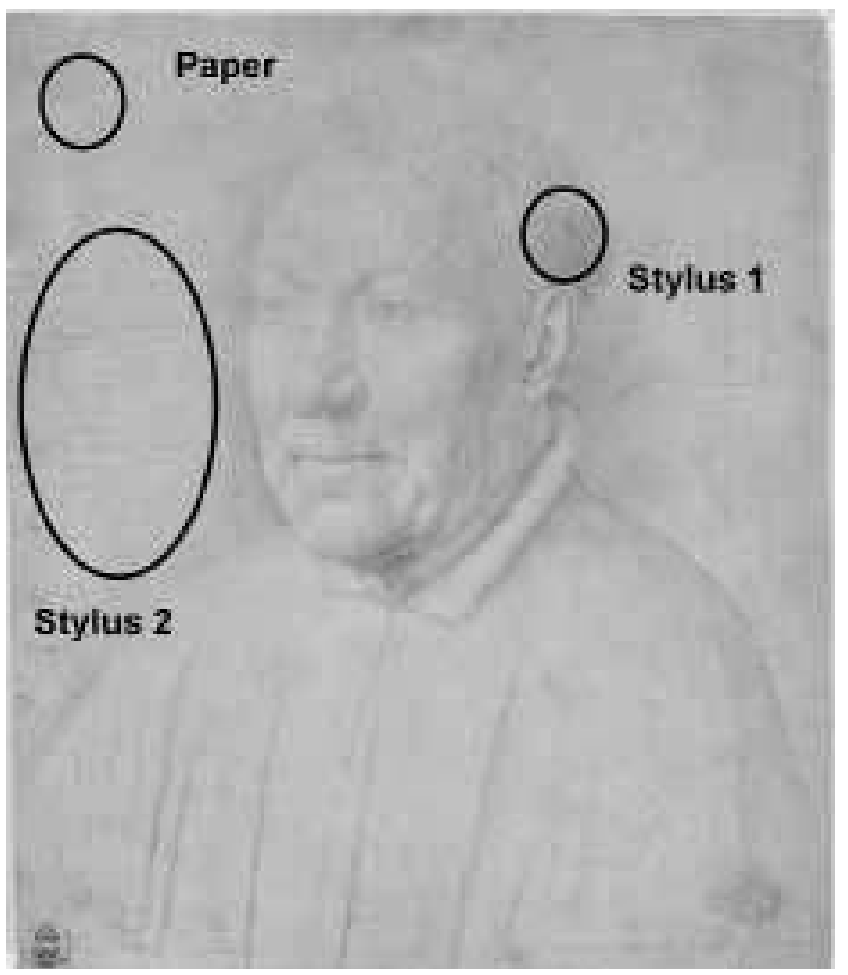

sciously used diverse metal points in order to make the most of the changing properties of different metal styli, and to achieve special graphic effects, such as the particular threedimensionality or profundity of this portrait.

It is thus possible to draw a conclusion regarding the genesis of the drawing. Van Eyck probably used first the pure silver stylus for drawing the face, the robe, and the hair of the figure. The cross line was also made with this stylus. The hatchings on the left and on the right of the head were made with another copper-containing silver point, which emphasizes the plasticity of the portrait. Then, the eyes and other parts of the portrait were intensified using the gold stylus. With the same stylus, the letters on the face were inscribed (Reiche et al., 2004b).

The next example provides an insight into the fabrication techniques of Viking gold objects. The so-called 'Hiddensee Gold' objects (Fig. 2) are said to have been washed ashore after two great storm tides in 1872 and 1874, and saved by fishermen from Neuendorf, Germany. From there, they came to their present whereabouts, the Cultural and Historical Museum of Stralsund, under somewhat adventurous circumstances. The 16 objects, with a total weight of $600 \mathrm{~g}$, have been manufactured around $1000 \mathrm{AD}$ in a Viking workshop. The first results showed a great homogeneity of the different gold alloy of all sixteen objects, except

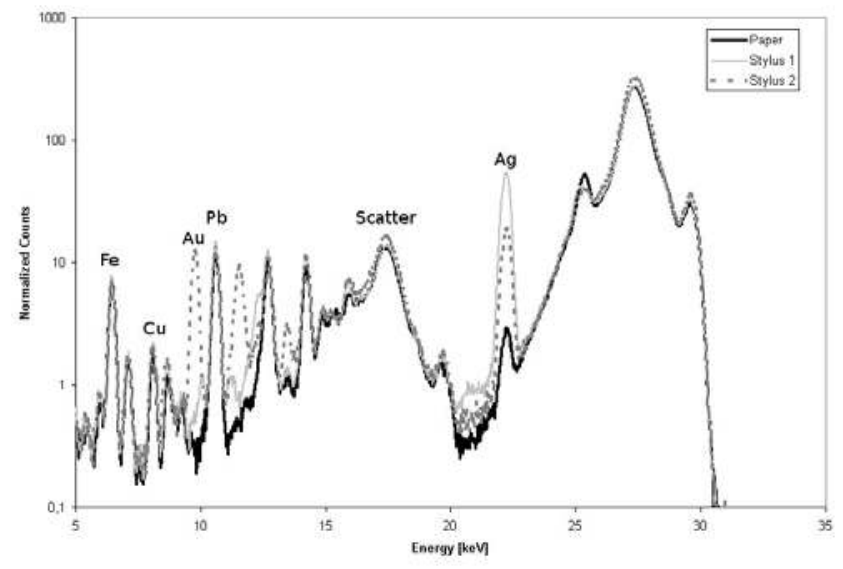

Figure 1: The drawing "Portrait of Cardinal Albergati" by Jan van Eyck (Kupferstichkabinett, Dresden, Germany, inv. no. C775). The plot shows a comparison of synchrotron-induced X-ray fluorescence spectra of a silver mark (stylus 1), a gold mark (stylus 2), and the paper with preparation backing measured with an excitation energy of $30 \mathrm{keV}$.

Figure 1: Le dessin Portrait du Cardinal Albergati par Jan van Eyck (Kupferstichkabinett, Dresde, Allemagne, inv. no. C775). Le graphique montre la comparaison des spectres obtenus par fluorescence de rayons $X$ induite par radiation de synchrotron de marques en argent (stylus 1) et en or (stylus 2) et du papier avec la préparation d'entoilage mesurés avec une énergie d'excitation de $30 \mathrm{keV}$.

for the brooch, the neck ring, and one of the cross-shaped pendants (no. 12). This finding was not surprising for the neck ring, which was processed with the help of a different technique (twisted wire instead of soldered sheet metal, wire, and granules), and not even for the brooch, which is a unique piece among the filigree decorated objects. However, there is no answer yet to the question of why the crossshaped pendant no. 12 has a significantly lower gold content than the other nine cross-shaped pendants. Perhaps it was produced separately and later added to the set? Another important result concerns the composition of the solder. Remnants of metallic solder distributed on the sheets could clearly be seen under the microscope. For the solder, gold had been alloyed with other types of metal so that the melting point was significantly lower than that of the gold alloy of sheets and decorations. Upon heating, the sheets and decorations were connected by the solder without melting themselves. Normally, the melting point of pure gold is $1084^{\circ} \mathrm{C}$. By adding silver or copper to the gold, the melting point can be reduced to a temperature between $850^{\circ} \mathrm{C}$ and $975^{\circ} \mathrm{C}$, depending on the exact proportions of the different metals. Our investigations of pendant no. 13, for example, confirm the presence of a high amount of copper in the solder (Armbruster et al., 2004). 

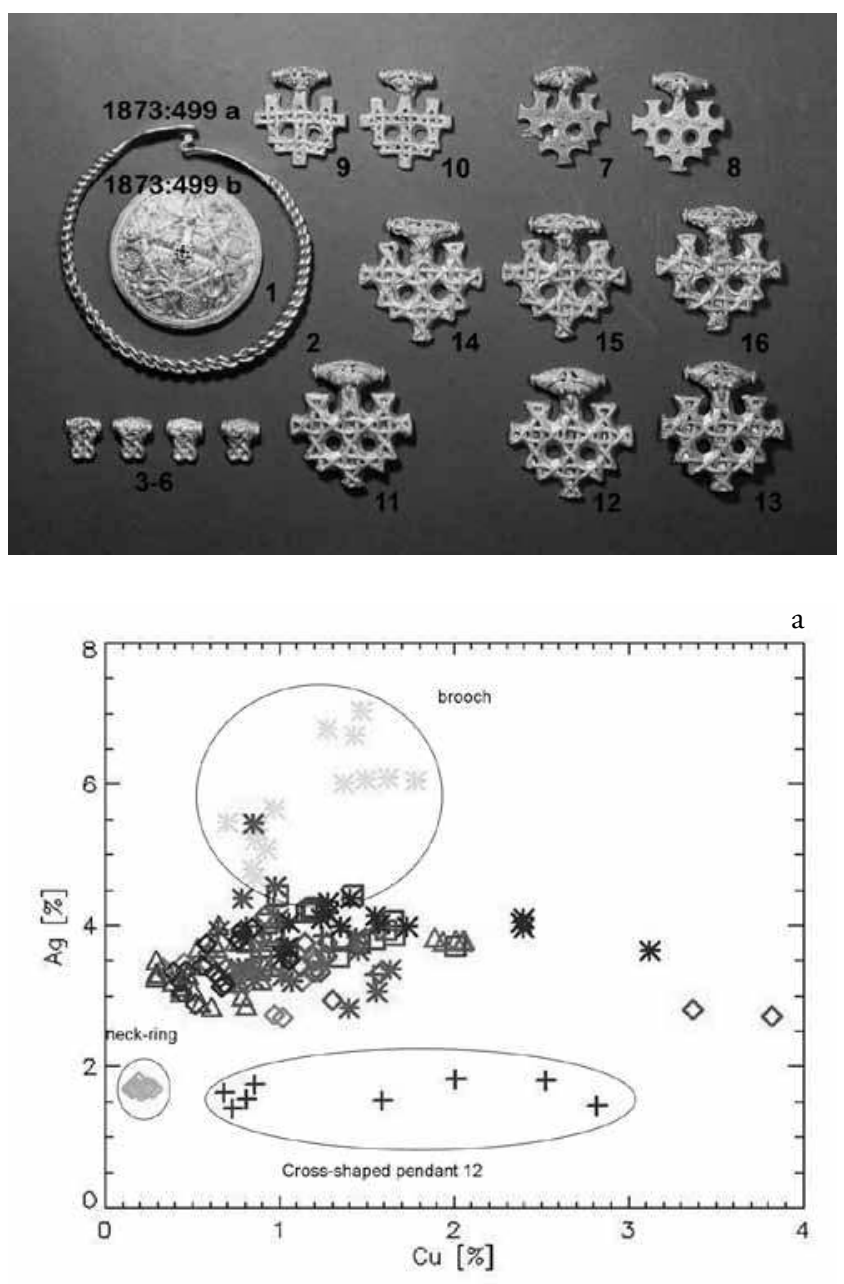

The provenance of gold objects based on elemental analysis is problematic, due to the frequent recycling of this precious material. However, for very old objects, it can be assumed that no recycling took place, and that the fingerprint of trace elements in the gold object is similar to that of the original gold. The third example presented in this publication, the 'Sky Disc of Nebra' (Fig. 3), was manufactured around 2000 $\mathrm{BC}$ and is featuring the earliest record of Central European astronomy known to date. The question that needed to be answered with SR-XRF was whether the composition of the different gold parts was the same, or if it had changed during different periods of completion according to the purpose of the disc. The analysis of minor components such as silver and tin provided the basis for a cluster analysis resulting in the separation of three distinctly different groups:

1. sun, moon and the majority of the stars;

2. horizon and one single-shifted star;

3. the so-called bark.

Using these results, we were able to support the assumption of the archaeologists, that the disc was manufactured

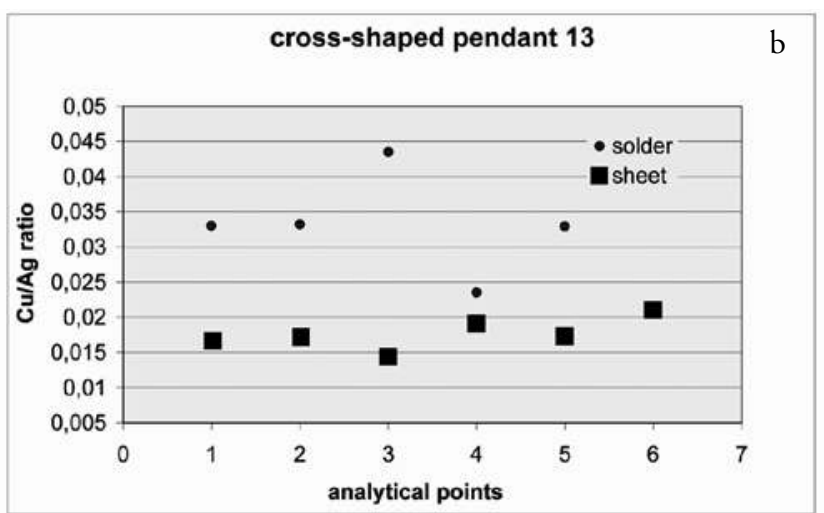

Figure 2: (See colour plate) The Hiddensee Gold treasure (Kulturhistorisches Museum Stralsund, Germany, inv. no. 1873: 499a et cetera). The scatter plot (a) shows the different compositions of the brooch, the neck-ring, and pendant no. 12. In the plot (b), the increased copper content of the solder can be seen. Figure 2: (Voir planche couleur) Le trésor de Hiddensee (Kulturhistorisches Museum Stralsund, Allemagne, inv $n^{\circ} 1873$ : 499a). Le graphique ci-contre (a) montre les différentes compositions de la broche, du ras de cou et du pendentif $n^{\circ} 12$. Le graphique ci-dessus (b) met en évidence l'augmentation de la teneur en cuivre pour la soudure.

in several phases, representing progress in knowledge and a change of religion and purpose. Additionally, we were able to identify the Carpathian basin as the most likely source of the gold. Using copper from Austria, and a 'technology transfer' from Mycenae (Greece), the manufacturing of the Nebra Sky Disk can be considered as a very early endeavour based on a joint European experience, possibly with contributions indebted to the symbolism of Egypt or the Levant (Pernicka et al., 2003).

\section{Summary}

The special requirements for the use of a synchrotron and the advantages of synchrotron radiation have been discussed above. SR-XRF made it possible to characterize small amounts of metal, as in the case of the silverpoint drawings, analyse big objects such as the Sky Disc of Nebra, and to measure the composition of objects on a small scale, as in the case of the solder used for the Hiddensee gold.

It has been shown that knowledge about the composition of the material can provide significant information about the origin and insights into the manufacturing process of an object. While the examples presented above are covering the main topics related to the analysis of ancient 


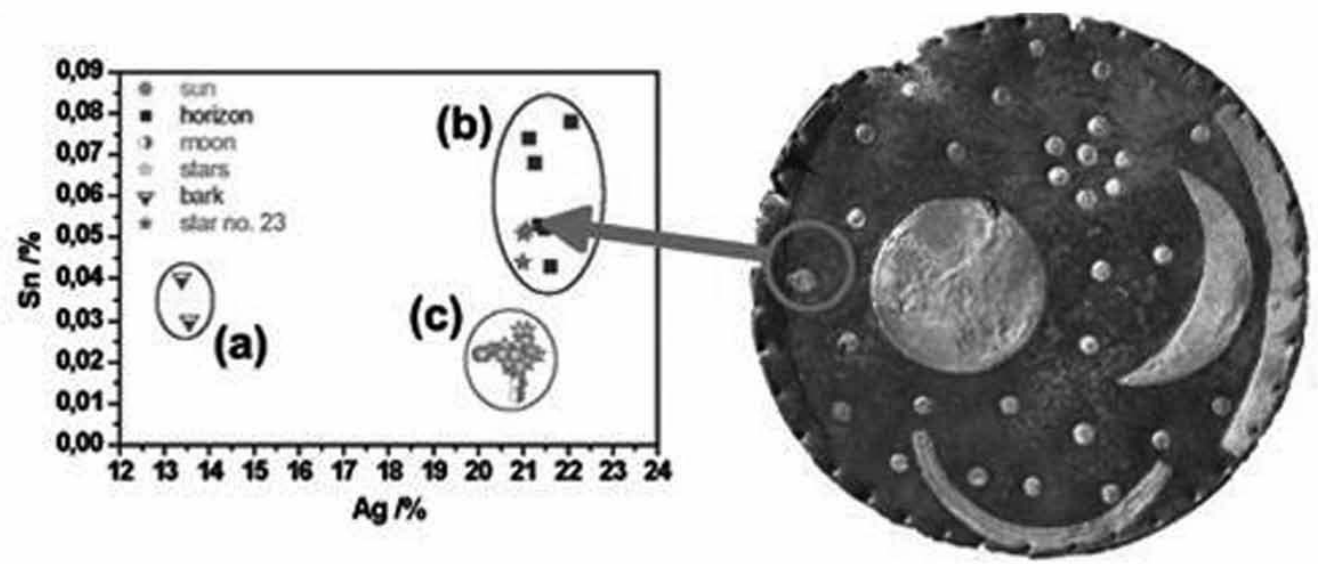

Figure 3: (See colour plate) The Sky Disk of Nebra (Landesmuseum für Vorgeschichte, Halle, Germany, inv. no. HK2002:1649a). The measured silver and tin contents of the gold applications are shown in the scatter plot. The three groups are clearly recognisable: (a) bark; (b) star no. 23 and horizon; (c) the remaining stars with moon and sun.

Figure 3 : (Voir planche couleur) Le disque céleste de Nebra (Landesmuseum für Vorgeschichte, Halle, Allemagne, inv. no. HK2002: 1649a). Les teneurs en argent et en étain mesurées pour les applications en or sont indiquées sur le graphique. Les trois groupes sont clairement reconnaissables: (a) écorce; (b) étoile $n^{\circ} 23$ et horizon; (c) les autres étoiles avec la lune et le soleil.

gold with SR-XRF, it should be mentioned that there are also other techniques able to offer useful information. For example, X-Ray Diffraction (XRD) was used to investigate the weathering of gilding decorations (Lluveras et al., 2008). X-ray Absorption Spectroscopy (XANES and EXAFS) and Small Angle X-ray Scattering (SAXS) are useful tools for characterizing nano particles in gold ruby glass (Eichelbaum et al., 2007).

In the future, the use of SR-XRF to characterize the Berlin Gold Hat (Museum für Vor- und Frühgeschichte, Staatliche Museen zu Berlin, Germany) and the Skythian Gold Treasures from Vettersfelde and Maikop (Antikensammlung, Staatliche Museen zu Berlin, Germany) will bring exciting new insights into the past.

\section{Acknowledgements}

The authors would like to thank our colleagues I. Reiche, M.F. Guerra, B. Armbruster, H. Eilbracht, A. Grüger, C.H. Wunderlich and E. Pernicka for the good collaboration. A special compliment for all the art historians and archaeologists involved, for the confidence to bring these unique objects to our beam line. The BESSY team is acknowledged for their good cooperation.

\section{References}

Adams, F., Janssens, K. and Snigirev, A., 1998. Microscopic $\mathrm{X}$-ray fluorescence analysis and related methods with laboratory and synchrotron radiation sources - Plenary lecture. Journal of Analytical Atomic Spectrometry 13(5): 319-331.

Armbruster, B., Eilbracht, H., Grüger, A., Radtke, M., RIESEMEIER, H. and ReICHE, I., 2004. The Vikings in Berlin: SR-XRF analyses of the Hiddensee gold jewellery. BESSY Scientific Highlights 2004: 32-33.

Eichelbaum, M., Rademann, K., Weigel, W., Lochel, B., RADTKe, M. and Muller, R., 2007. Gold-ruby glass in a new light: On the microstructuring of optical glasses with synchrotron radiation. Gold Bulletin 40(4): 278-282.

Görner, W., Eichelbaum, M., Matschat, R., Rademann, K., Radtke, M., Reinholz, U. and Riesemeier, H., 2006. Nondestructive investigation of composition, chemical properties and structure of materials by synchrotron radiation. Insight 48(9): 540-544.

Guerra, M.F., Calligaro, T., Radtke, M., Reiche, I. and RIESEMEIER, H., 2005. Fingerprinting ancient gold by measuring Pt with spatially resolved high energy Sy-XRF. Nuclear Instruments and Methods B 240(1-2): 505-511.

Guerra, M.F., Radtke, M., Reiche, I., Riesemeier, H. and STRUB, E., 2008. Analysis of trace elements in gold alloys by SR-XRF at high energy at the BAMline. Nuclear Instruments and Methods B 266(10): 2334-2338. 
Lluveras, A., Boularand, S., Roque, J., Cotte, M., Giraldez, P. and VENDRELL-SAZ, M., 2008. Weathering of gilding decorations investigated by SR: Development and distribution of calcium oxalates in the case of Sant Benet de Bages (Barcelona, Spain). Applied Physics A: Materials Science and Processing 90(1): 23-33.

Pernicka, E., Radtke, M., Riesemeier, H. and Wunderlich, C-H., 2003. European Network of Competence at 1600 BC. BESSY Scientific Highlights 2003: 8-9.

Reiche, I., Berger, A., Gorner, W., Merchel, S., RadtKe, M., Riederer, J., Riesemeier, H. and Roth, M., 2004a. Following the traces of Albrecht Dürer: analysis of silverpoint drawings by spatially resolved synchrotron-induced X-ray fluorescence analysis. Nuclear Instruments and Methods B 226(1-2): 83-91.

Reiche, I., RadtKe, M., Berger, A., Gorner, W., Ketelsen, T., Merchel, S., Riederer, J., Riesemeier, H. and Roth, M., 2004B. Spatially resolved synchrotron-induced X-ray fluorescence analyses of metal point drawings and their mysterious inscriptions. Spectrochimica Acta B: Atomic Spectroscopy 59(1011): 1657-1662.

Sole, V.A., Papillon, E., Cotte, M., Walter, P. and Susini, J., 2007. A multiplatform code for the analysis of energy-dispersive X-ray fluorescence spectra. Spectrochimica Acta B: Atomic Spectroscopy 62(1): 63-68.

Strub, E., Radtke, M., Reinholz, U., Riesemeier, H. and Remiкova, E., 2008. Measurements with compound refractive lenses at the "BAMline". Nuclear Instruments and Methods B 266(10): 2165-2168.

Vincze, L., Janssens, K., Adams, F. and Jones, K.W., 1995. A general Monte Carlo simulation of energy-dispersive X-ray fluorescence spectrometers. Part 3. Polarized polychromatic radiation, homogeneous samples. Spectrochimica Acta B: Atomic Spectroscopy 50(12): 1481-1500. 